\title{
Pengembangan Kemasan Produk Khansa Pizza Untuk Meningkatkan Penjualan Dengan Menggunakan Metode Quality Function Deployment (QFD)
}

\author{
Sanusi ${ }^{1}$ \\ 1Jurusan Teknik Industri Sekolah Tinggi Teknik Ibnu Sina \\ sanusi@stt-ibnusina.ac.id \\ M. Ansyar Bora ${ }^{2}$ \\ 2Jurusan Teknik Industri Sekolah Tinggi Teknik Ibnu Sina \\ ansyar@stt-ibnusina.ac.id \\ Bayu. $A^{3}$ \\ ${ }^{3} J u r u s a n$ Teknik Industri Sekolah Tinggi Teknik Ibnu Sina \\ Bayu_A@gmail.com
}

\begin{abstract}
ABSTRAK
Kompetisisi dunia bisnis sekarang ini semakin ketat sehingga mengharuskan pelaku bisnis untuk melakukan inovasi dan pencarian idea-idea kreatif agar tetap bisa unggul dan bersaing, olehkarena itu kompitisi penjualan produk tidak hanya terbatas pada kualitas produk tapi juga kemasan produknya. Salah satu usaha yang bisa dilakukan untuk menghadapi kompetisi tersebut adalah melalui rancangan kemasan. Tujuan dari penelitian ini adalah untuk menghasilkan rancangan kemasan yang memenuhi keinginan pelanggan. Untuk mengetahui keinginan pelanggan, data dikumpulkan dengan menyebarkan kuisener ke 95 pelanggan yang datang ke Usaha Kecil dan Menengah Pizza Khansa secara random sebagai sample dalam penelitian ini. Semua keinginan pelanggan diterjemahkan kedalam bahasa teknik dengan menggunakan quality function deployement (QFD). Ada 10 atribut dan 6 karekteristik teknikal diidentifikasi. Berdasarkan pengembangan konsep pengembangan kemasan yang diperoleh, rancangan kemasan mempunyai fungsi untuk melindungi Pizza dan kemasan dari uap panas, memiliki bentuk segi empat dengan ukuran panjang $14,5 \mathrm{~cm}$ x lebar $14,5 \mathrm{~cm}$, tinggi $2,5 \mathrm{~cm}$ dan desain berwarna coklat kombinasi merah serta bahan kemasan menggunakan eflute, tambahan kertas minyak dan menggunakan digital print. Implikasi dari penelitian ini bisa meningkatkan kualitas Pizza dan penjualan Pizza Khansa di masa depan. Selain mendapatkan design yang bisa memenui keinginan pelanggan, rancangan yang diperoleh juga dapat meningkatkan daya tarik bagi calon pelaggan yang belum menjadi pelanggan tetap.
\end{abstract}

KATA KUNCI: perancangan,kemasan, Quality Function Development, pelanggan

\section{PENDAHULUAN}

Pemasaran merupakan suatu proses merencanakan dan menjalankan serangkaian konsep, promosi dan konsep distribusi terhadap suatu ide-ide, barang dan jasa untuk menciptakan pertukaran yang memuaskan individu, organisasi dan masyarakat. untuk 69 | L I S 2016 
merancang produk dengan baik, tim desain harus mengetahui apa yang akan mereka rancang, dan apa yang customer harapkan dari produk tersebut. Kemasan secara sederhana dapat diartikan suatu benda yang digunakan untuk membungkus atau untuk melindungi suatu barang agar rapi atau bersih. Kemasan memiliki fungsi yang sangat penting untuk suatu benda yang digunakan untuk membungkus atau untuk melindungi suatu barang agar rapi atau bersih. Disimpulkan bahwa kemasan adalah suatu kegiatan yang di lakukan oleh perusahaan untuk mendapatkan kemasan yang baik maupun menarik untuk pelanggan

Dalam penelitan ini Perkembangan dan perubahan kemasan sangat berpengaruh pada peningkatan penjualan. Pada tahun 2013 data penjualan dalam setahun sebanyak 12697 kotak dan pada tahun 2014 sampai dengan 2015 sebanyak 29483 kotak. Salah satu faktor meningkatnya penjualan ini dikarenakan perubahan kemasan yang menjadi lebih kecil dan dianggap sesuai dengan ukuran pizza mini. Pengembangan kemasan ini juga bertujuan untuk membuat strategi berkembangnya UKM Khansa dari sisi pengemasan yang sesuai dengan kebutuhan dan keinginan customer serta untuk meningkatkan penjualan.

Kemasan yang tidak tepat bisa menjadi salah satu alasan karena dapat mengakibatkan produk didalamnya. Desain kemasan diproses tidak hanya memperhatikan kepentingan konsumen tetapi juga produsen. Desain kemasan dapat memberikan informasi- informasi tentang produk mengenai bentuk fisik produk, label dan sisipan instruksi detail.

\section{KAJIAN KESUSASTERAAN}

Perancangan adalah proses penerapan berbagai teknik dan prinsip dengan tujuan untuk mentransformasikan hasil analisis ke dalam bentuk yang memudahkan pengimplementasian. Fungsi perancangan memegang peranan penting dalam mendefinisikan bentuk fisik produk agar dapat memenuhi kebutuhan pelanggan. Dalam konteks tersebut tugas bagian perancangan mencakup desain engineering (mechanic, electric, software, etc) dan desain industri (estetika, ergonomics, user interface). Menurut Robert (2004), pengembangan produk merupakan keputusan yang memiliki resiko tinggi bagi perusahaan karena memerlukan biaya yang tinggi serta kemungkinan produk baru tersebut gagal dalam pemasaran. Dengan demikian usaha pengembangan produk yang berhasil akan memberikan imbalan yang seimbang dengan resiko yang ditanggung oleh perusahaan. Fokus pada pengembangan produk sangat penting dilakukan dan dapat dijadikan sebagai strategi bersaing agar perusahaan selalu mendapatkan permintaan jauh sebelum produk tersebut secara penuh dibuat. Aktivitas Perancangan, Pembentukan Rancangan, Eksplorasi Rancangan dilakukan untuk memperoleh rancangan yang diinginkan oleh pelanggan.

Kotler dan Amstrong (2012) mendefinisikan "packaging involves designing and producing the container or wrapper for a product" yang artinya adalah proses kemasan melibatkan kegiatan mendesain dan memproduksi. Fungsi utama dari kemasan sendiri yaitu untuk melindungi produk agar produk tetap terjaga kualitasnya kemasan terdiri dari 3 dimensi, yaitu: desain grafis, struktur desain, dan informasi produk.

1. Desain Grafis

Desain grafis adalah dekorasi visual pada permukaan, dan terdiri dari empat sub dimensi, yaitu: nama merek, warna, tipografi, dan gambar.

2. Struktur Desain

Struktur desain berkaitan dengan fitur-fitur fisik kemasan, dan terdiri dari 3 subdimensi: bentuk, ukuran, dan material.

3. Informasi Produk 
Salah satu fungsi kemasan adalah untuk mengkomunikasikan produk melalui informasi yang tertera dalam desain kemasan. Informasi produk dapat membantu konsumen dalam membuat keputusan pembelian dengan lebih hati-hati. (Silayoi \& Speece, 2005) dalam jurnal Priscilla,C., dan J. Ellyawti .

Menurut Wijaya (2011:11) suatu produk harus memiliki tingkat kualitas tertentu karena produk dibuat untuk memenuhi selera konsumen atau memuaskan pemakainya. Kualitas produk juga dapat mengurangi biaya (cost).

Dimensi Kualitas Produk

Menurut Garvin dalam Tjiptono (2008:93) menyatakan bahwa kualitas produk terdiri atas delapan dimensi, yaitu:

1. Kinerja (Performance), yaitu efisiensi pencapaian tujuan utama sebuah produk. Pada umumnya kinerja yang lebih bagus identik dengan kualitas yang lebih baik.

2. Fitur (Features), adalah atribut produk yang melengkapi kinerja dasar sebuah produk.

3. Reliabilitas (Reliability), yaitu kemampuan sebuah produk untuk tetap berfungsi secara konsisten selama usia desainnya. Sebuah produk akan dikatakan reliabel (andal) apabila kemungkinan kerusakan atau gagal dipakai selama usia desainnya sangat rendah.

4. Kesesuaian dengan spesifikasi (Conformance to specification), yaitu sejauh mana karakteristik desain dan operasi sebuah produk memenuhi standar-standar yang telah ditetapkan sebelumnya.

5. Daya tahan (Durability), berkaitan dengan tingkat kemampuan sebuah produk mentolerir tekanan, stres atau trauma tanpa mengalami kerusakan berarti.Serviceability, yaitu kemudahan mereparasi sebuah produk. Sebuah produk dikatakan sangat serviceable apabila bisa direparasi secara mudah dan murah. Banyak produk yang membutuhkan reparasi oleh teknisi, seperti halnya peralatan elektronik, komputer, dan otomotif. Bilamana reparasi tersebut cepat dan mudah diakses, maka produk tersebut dapat dikatakan memiliki tingkat serviceability yang tinggi.

6. Estetika, yaitu daya tarik produk terhadap panca indera.

7. Persepsi kualitas (Perceived quality), yaitu citra dan reputasi produk serta tanggung jawab perusahaan terhadapnya. Biasanya karena kurangnya pengetahuan pembeli akan atribut produk atau fitur produk yang akan dibeli, maka pembeli mempersepsikan kualitasnya dari aspek harga, nama merek, iklan, reputasi perusahaan, maupun negara pembuatnya.

\section{METODE PENELITAN}

Penelitian ini menggunakan metode QFD dengan tahapan awal yaitu wawancara responden. Selanjutnya, penentuan atribut mengacu hasil wawancara dan atribut lain berdasarkan hasil studi literatur yang kemudian dikonfirmasikan kepada responden sehingga menjadi Voice Of Customer. Untuk mengetahui informasi mengenai tingkat kepentingan, kepuasan dan harapan responden digunakan kuesioner. Kemudian, dilakukan penghitungan tingkat kepentingan, kepuasan dan harapan responden. Selanjutnya, penentuan karakteristik teknis dan kemudian pembuatan House Of Quality (HOQ). Pengembangan konsep rancangan kemasan dilakukan berdasar informasi pada HOQ dan literatur. Selanjutnya dilakukan penarikan kesimpulan dari penelitian yang telah dilakukan. Kemudian, diikuti penyampaian saran-saran yang dapat nantinya dapat ditindaklanjuti oleh pembaca ataupun peneliti sesudahnya.

71 | L IS 2016 


\section{HASIL DAN PEMBAHASAN}

Penelitian dilakukan agar mendapatkan rancangan baru sesuai dengan keinginan ppelanggan. Penyebaran kuisener dikakukan kepada 95 orang reseponden dengan menggunkan Non Propability Sampling jenis accidental Sampling. Mengidentifikasi keinginan konsumen terhadap kedalam dalam bentuk atribut produk. Untuk mengetahui keinginan konsumen terhadap kemasan pizza, maka dalam pengumpulan data dilakukan pengelompokan data berdasarkan atribut kemasan yang diinginkan.

Tabel 1. Data atribut kemasan pizza yang diinginkan konsumen

\begin{tabular}{clll}
\hline No & & \multicolumn{2}{c}{ Atribut } \\
\hline & Primer & \multicolumn{1}{c}{ Sekunder } & \multicolumn{1}{c}{ Tersier } \\
\hline 1 & Fungsional & Utama & Melindungi makanan \\
& & Tambahan & Tahan dari uap panas \\
\hline 2 & Desain & Bentuk Rangka & Segi empat \\
& & Dimensi PXLXT & $14,5 \mathrm{~cm} \times 14,5 \mathrm{~cm} \times 2,5 \mathrm{~cm}$ \\
& Warna Kemasan & Coklat+merah \\
& & Tambahan & Adanya inovasi pada desain \\
& & Terdapat logo halal \\
\hline \multirow{3}{*}{3} & Bahan & Rangka & E flute \\
& & Stiker & Digital print \\
& & Tambahan & Tahan dari minyak \\
\hline
\end{tabular}

Tahapan selanjutnya menentukan tingkat kepentingan relatif dari atribut produk. Penentuan tingkatan kepentingan relatif atribut ini dilakukan dengan memberikan bobot persentase pada masing-masing atribut dengan menggunakan skala prioritas.

Tabel 2 Menentukan tingkat kepentingan

\begin{tabular}{|c|c|c|c|c|}
\hline \multirow[t]{2}{*}{ No } & \multicolumn{3}{|c|}{ Atribut } & \multirow{2}{*}{$\begin{array}{l}\text { Tingkat } \\
\text { Kepentingan }\end{array}$} \\
\hline & Primer & Sekunder & Tersier & \\
\hline \multirow[t]{2}{*}{1} & Fungsional & Utama & Melindungi makanan & 5 \\
\hline & & Tambahan & Tahan dari uap panas & 4 \\
\hline \multirow[t]{5}{*}{2} & Desain & Bentuk Rangka & Segi empat & 4 \\
\hline & & Dimensi PXLXT & $14,5 \mathrm{~cm} \times 14,5 \mathrm{~cm} \times 2,5 \mathrm{~cm}$ & 4 \\
\hline & & Warna Kemasan & Coklat + merah & 4 \\
\hline & & Tambahan & $\begin{array}{l}\text { Adanya inovasi pada desain } \\
\text { Terdapat logo halal }\end{array}$ & $\begin{array}{l}5 \\
4\end{array}$ \\
\hline & Bahan & Rangka & E flute & 4 \\
\hline \multirow[t]{2}{*}{3} & & Stiker & Digital print & 4 \\
\hline & & Tambahan & Tahan dari minyak & 4 \\
\hline
\end{tabular}

72 | L I S 2016 
Atribut yang telah diterjemahkan kedalam karakerostik teknik diletakan pada bagian vertikal ditepi sebelah kiri sedangkan karakteristik teknik dibagian horizontal tepi atas. Matriks antara atribut produk dan karakteristik teknik dapat dilihat pada tabel 3

Tabel 3 Matriks antara atribut

\begin{tabular}{|c|c|c|c|c|c|c|c|}
\hline $\begin{array}{l}\text { Ket }: \\
V=\text { Hubungan positif kuat } \\
\sqrt{ }=\text { Hubungan positif sedang } \\
X=\text { Hubungan negatif sedang } \\
X=\text { Hubungan negatif kuat }\end{array}$ & $\begin{array}{l}=4 \\
=3 \\
=2 \\
=1\end{array}$ & 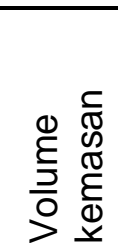 & 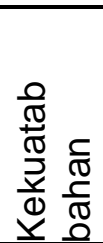 & 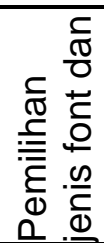 & 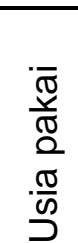 & 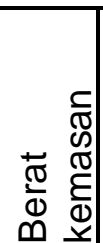 & 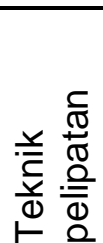 \\
\hline Melindungi makanan & & $\mathrm{V}$ & $\overline{\mathrm{V}}$ & $\bar{X}$ & $\bar{X}$ & $x$ & $x$ \\
\hline Tahan dari uap panas & & $\sqrt{ }$ & $\mathrm{V}$ & $\bar{X}$ & $\bar{X}$ & $\bar{X}$ & $\bar{X}$ \\
\hline Segi empat & & $\sqrt{ }$ & $x$ & $\sqrt{ }$ & $\bar{x}$ & $\bar{X}$ & $\mathrm{~V}$ \\
\hline $\begin{array}{l}\text { Dimensi PxlxT } 14,5 \mathrm{~cm} \mathrm{x14,5cm} \mathrm{x} \\
2 \mathrm{~cm}\end{array}$ & & $\sqrt{ }$ & $X$ & $\sqrt{ }$ & $X$ & $x$ & $x$ \\
\hline Coklat + merah & & $\mathrm{X}$ & $\mathrm{X}$ & $\mathrm{V}$ & $\mathrm{X}$ & $\mathrm{X}$ & $\bar{x}$ \\
\hline Adanya inovasi pada desain & & $x$ & $\sqrt{ }$ & $\sqrt{ }$ & $\mathrm{x}$ & $x$ & $\mathrm{~V}$ \\
\hline Terdapat logo halal & & $\bar{X}$ & $\bar{X}$ & $\sqrt{ }$ & $\bar{X}$ & $\bar{X}$ & $\bar{X}$ \\
\hline E flute & & $\sqrt{ }$ & $\sqrt{ }$ & $x$ & $\sqrt{ }$ & $x$ & $\sqrt{ }$ \\
\hline Digital print & & $\bar{X}$ & $\bar{X}$ & $\mathrm{~V}$ & $\mathrm{X}$ & $\bar{X}$ & $\mathrm{X}$ \\
\hline Tahan dari minyak & & $x$ & $\sqrt{ }$ & $\mathrm{X}$ & $\mathrm{X}$ & $\mathrm{X}$ & $\bar{X}$ \\
\hline
\end{tabular}

Selanjutnya mengidentifikasi hubungan antara sesama karakteristik teknik langkah ini bertujuan umtuk mengidentifikasi hubungan antara sesama karakteristik yang satu dengan yang lain, dapat dilihat pada gambar 1.

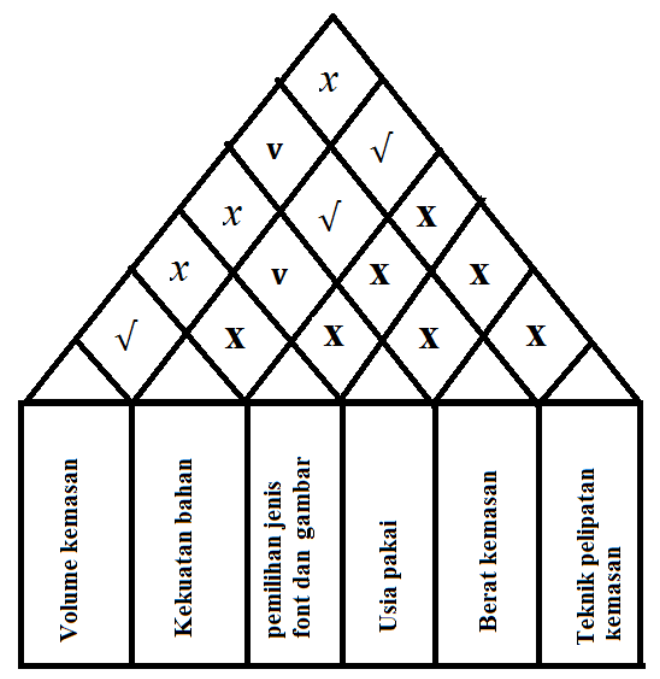

Gambar 1 Menentukan Target Pencapaian untuk Setiap Karakteristik teknik

Menentukan Target Pencapaian Pada langkah ini, ditentukan target yang harus di capai untuk masing-masing karakteristik teknik, tingkat kesulitan pembuatan produk, tingkat kepentingan dan perkiraan biaya tingkat masing-masing karakteristik teknik. 
a) Tingkat Kesulitan dengan total bobot $\mathbf{=} \mathbf{3 0}$

1. Volume kemasan $=12 / 30 \times 100 \%=43.3 \%$ (jika total target $43.3 \%$ makan nilai tingkat kesulitannya adalah 5 dan tergolong sulit)

2. Kekuatan bahan $=14 / 30 \times 100 \%=46.6 \%$ (jika total target $50.0 \%$ makan nilai tingkat kesulitannya adalah 5 dan tergolong sulit)

3. Pemilihan jenis font $=6 / 30 \times 100 \%=20 \%$ (jika total target $20 \%$ makan nilai tingkat kesulitannya adalah 1 dan tergolong mudah)

4. Usia pakai $=9 / 30 \times 100 \%=30 \%$ (jika total target $30.0 \%$ makan nilai tingkat kesulitannya adalah 3 dan tergolong cukup mudah)

5. Berat kemasan $=10 / 30 \times 100 \%=33.3 \%$ (jika total target $33.3 \%$ makan nilai tingkat kesulitannya adalah 3 dan tergolong cukup mudah)

6. Teknik pelipatan kemasan $=8 / 30 \times 100 \%=26.6 \%$

(jika total target $26.6 \%$ makan nilai tingkat kesulitannya adalah 3 dan tergolong cukup mudah)

b) Tingkat Kepentingan dengan total bobot $=\mathbf{1 2 0}$

1. Volume kemasan $=23 / 120 \times 100 \%=19.1 \%$

(jika nilai tingkat kepentingan $19.1 \%$ maka tingkat kepentingannya adalah 19 dan terglong penting)

2. Kekuatan bahan $=23 / 120 \times 100 \%=19.1 \%$

(jika nilai tingkat kepentingan $19.1 \%$ maka tingkat kepentingannya adalah 19 dan terglong penting)

3. Pemilihan jenis font dan gambar $=25 / 120 \times 100 \%=20.8 \%$

(jika nilai tingkat kepentingan 28.8\% maka tingkat kepentingannya adalah 21 dan terglong penting)

4. Usia pakai $=15 / 120 \times 100 \%=12.5 \%$

(jika nilai tingkat kepentingan 12.5\% maka tingkat kepentingannya adalah 12 dan terglong cukup penting penting)

5. Berat kemasan $=14 / 120 \times 100 \%=11.6 \%$ (jika nilai tingkat kepentingan $11.6 \%$ maka tingkat kepentingannya adalah 11 dan terglong cukup penting)

6. Teknik pelipatan kemasan $=20 / 120 \times 100 \%=16.6 \%$

(jika nilai tingkat kepentingan $16.6 \%$ maka tingkat kepentingannya adalah 16 dan terglong penting)

c) Perkiraan Biaya dengan total bobot $\mathbf{=} \mathbf{2 0}$

1. Volume kemasan $=5 / 20 \times 100 \%=25 \%$

(jika nilai perkiraan biaya adalah $25 \%$ maka nilai perkiraan biaya adalah 25 dan terglong mahal)

2. Kekuatan bahan $=5 / 20 \times 100 \%=25 \%$

(jika nilai perkiraan biaya adalah $25 \%$ maka nilai perkiraan biaya adalah 25 dan terglong mahal)

3. Pemilihan jenis font dan gambar $=1 / 20 \times 100 \%=5.0 \%$ (jika nilai perkiraan biaya adalah $5.0 \%$ maka nilai perkiraan biaya adalah 5 dan terglong murah) 
4. Usia pakai $=3 / 20 \times 100 \%=15 \%$

(jika nilai perkiraan biaya adalah $15 \%$ maka nilai perkiraan biaya adalah 15 dan terglong murah)

5. Berat kemasan $=3 / 20 \times 100 \%=15 \%$

(jika nilai perkiraan biaya adalah $15 \%$ maka nilai perkiraan biaya adalah 15 dan terglong murah)

Tahapan selanjutnya adalah menyusun House Of Quality merupakan gabungan semua karakteristik teknik, atribut yang di inginkan konsumen, posisi kemasan dan pesaing terhadap atribut yang sama. Semuanya dibuat dalam rumah mutu dengan menggunakan metode QFD dan dapat dilihat pada gambar berikut.

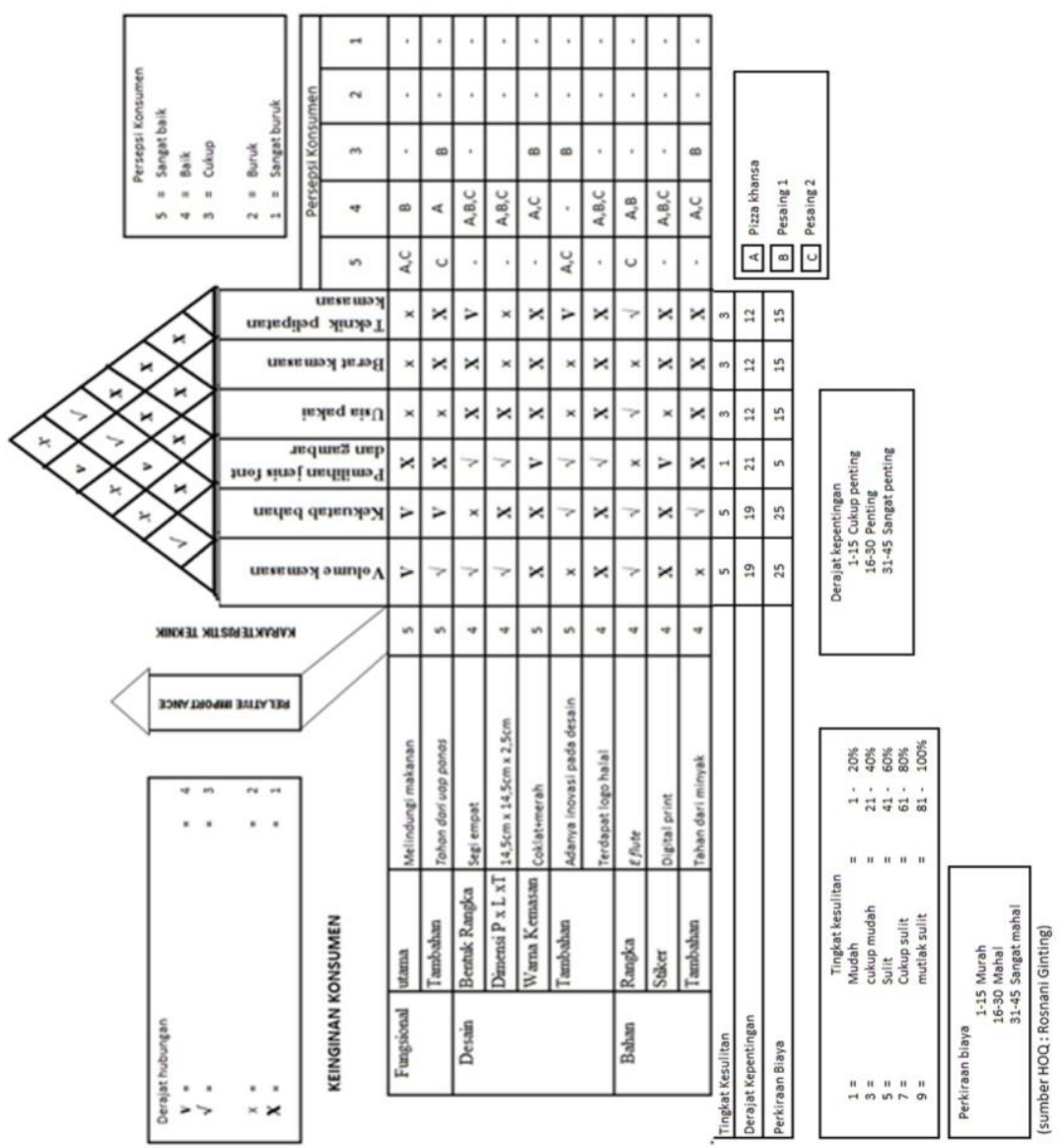

Gambar 2: House Of Quality dari Quality Funtiction Development (QFD) pizza Khansa

Atribut kemasan Pizza Khansa berdasarkan hasil Kuisioner yang telah diolah kedalam rumah kualitas QFD 

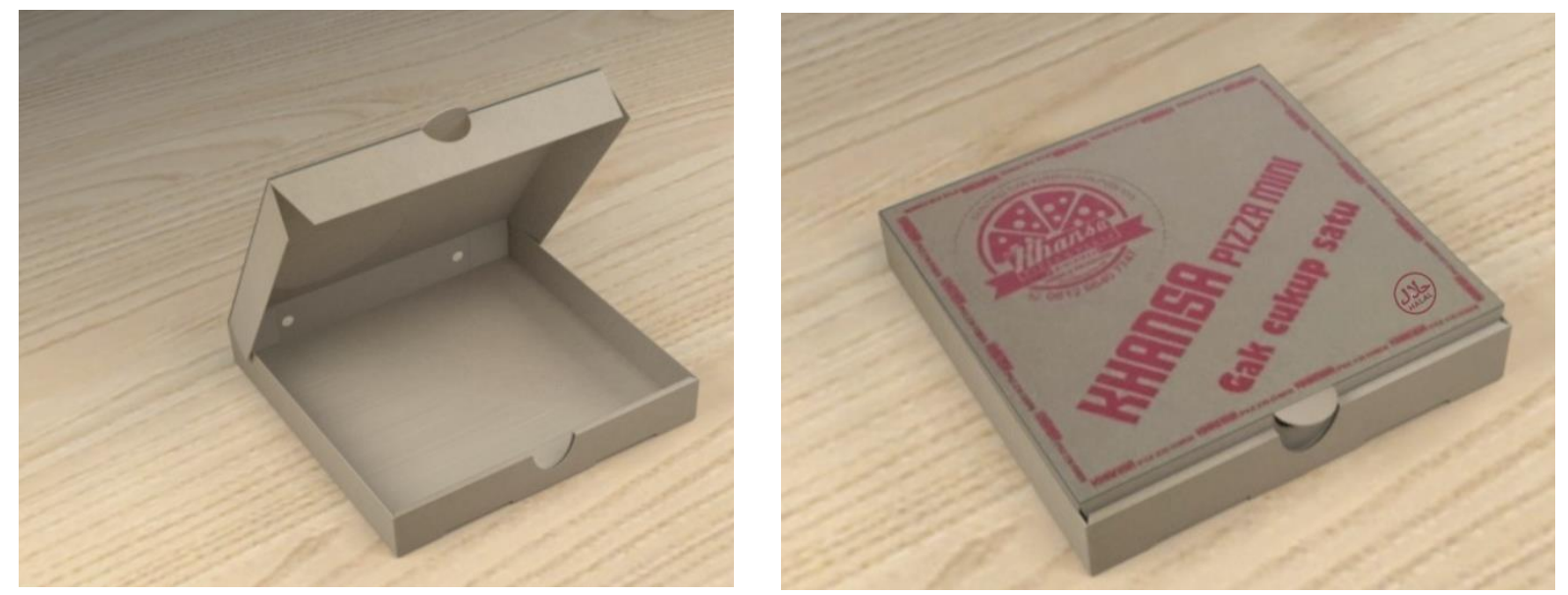

Gambar 3: Desain usulan kemasan pizza Khansa dengan metode QFD

Keterangan:

1. Fungsional:

2. Desain:
a. Melindungi makanan
b. Tahan dari uap panas
a. Segi empat
$2,5 \mathrm{~cm}$
b. Coklat + merah
d. Panjang $14,5 \mathrm{~cm} \times$ lebar $14,5 \mathrm{~cm} \times$ tinggi
e. Adanya inovasi pada desain

c. Terdapat logo halal

3. Bahan
a. E-flute
b. Digital Printing
c. Tahan dari minyak

Terdapat perbedaan yang terjadi antara rancangan yang dilakukan oleh pemilik usaha dan rancangan yang diinginkan oleh pelanggan. Perbedaan perspektif tersebut tentu saja menjadikan nilai tambah dan ide baru bagi pemilik pizza untuk merancang kemasan yang jauh lebih baik.

\section{5}

\section{KESIMPULAN}

Pembuatan rancangan kemasan pizza Khansa dengan menggunakan metode House Of Quality dari Quality Function Development (QFD) dilakukan dengan melihat keinginan dari konsumen (VOC) dan menerjemahkannya menjadi bahasa teknis (karakteristik teknik). Diperolehlah 10 atribut dan 6 karakteristik teknis. Berdasarkan pengembaganan konsep rancanganan yang dihasilkan rancangan kemasan memiliki fungsi melindungi makanan dan kemasantahan dari uap panas, memiliki bentuk segi empat dengan ukuran panjang $14,5 \mathrm{~cm} x$ panjang $14,5 \mathrm{~cm} \times$ tinggi $2,5 \mathrm{~cm}$ dan desain berwarna coklat kombinasi merah serta bahan kemasan menggunakan e-flute, tambahan kertas minyak dan menggunakan digital print.

Strategi pengembangan produk kemasan pizza Khansa berfokus pada fungsi kemasan dan inovasi pada kemasan. Strategi yang digunakan untuk meningkatkan penjualan adalah inovasi dalam merancang kemasan dengan memanfaatkan kemasan sebagai daya tarik pembelian dengan menggunakan strategi desain pemanfaatan lobang udara kemasan 
menjadi sebuah strategi promosi dengan memberikan poin pada setiap kemasan pizza Khansa dan setiap poin tersebut memiliki daya tarik pembelian pizza.

\section{DAFTAR PUSTAKA}

Alfredo Tutuhatunewa, (2010), Aplikasi Metode Quality Function Deployment Dalam Pengembangan Produk Air Minum Kemasan, Jurnal Arika, Vol 4, No 1, 11-19.

Cahyorini \& Rusfian. 2011. The Effect of Packaging Design on Impulsive Buying. Journal of Administrative Science \& Organization.

Cenadi, C. S. (2000). Peranan Desain Kemasan dalam Dunia Pemasaran. Jurnal Nirmana, Volume 2, Nomor 1, 92-103

Dian Christianto, (2016), aplikasi metode quality function deployment untuk peningkatan kualitas ikan gurame di UKM Tembesi bengkel. (TA/2016). Unpublished undergraduate thesis, Putra Batam.

Kartika, D.L. (2012) Desain Pengembangan Produk SLIM BOX LED Dengan Metode QFD (Quality Function Deployment). (TA/2012). Unpublished undergraduate thesis, Sekolah Tinggi Teknik Ibnu Sina Batam.

Kotler,P., \&Amstrong, G. (2012). Principles Of Marketing Edisi 14, Global Edition.Pearson Prentice Hall.

Kotler, Philip., dan Kevin Lane Keller. 2009. Manajemen Pemasaran. Edisi 13. Jilid 2. Alih bahasa: Bob Sabran. Jakarta : Penerbit Erlangga.

Kriyantono, Rachmat, 2006, Teknik Praktis Riset Komunikasi, Jakarta: Kencana Prenada Group

Mario, C, P. (2015, September) the influence of prodeck quality, packaging and brand image against coustomer satisfaction in cigarette company dunhill Manado. Jurnal Fakultas Ekonomi dan Bisnis Jurusan Manajement.

Nilsson, Johan \& Ostrom, Tobias. (2005). Packaging as a Brand Communication Vehicle . Thesis of Lulea University of Technology

Okky,R,Y. (2015, Desember). Analisis Pengembangan Produk Berbasis Quality Function Deployment (QFD). Jurnal fakultas Bisnis dan Manajement,25-29

Priscilla, C., J, Ellyawati ( n.d.) Pengaruh Desain Kemasan Packaging Pada Implulsive Buyying. Jurnal Program Studi Manajement Fakultas Ekonmi

Raysha, F., Rahmaniyah,D.a., Ilham, P. (2012) Perancangan Kemasan Obat Tradisional Mengunakan Metode Quality Function Deployment (QFD). Jurnal Teknik Industri.

Robert, A. 2004. Strategic Management of Technology and Innovation. Prentice-Hall. New York 
Rosnani Ginting. Perancangan Produk. Edisi pertama Yogyakarta, graham Ilmu tahun 2010

Rudesty Armelya. (2015) Analisa Kepuasan Pelanggan Terhadap Pelayanan Jasa Surat Khusus (SKH) Pada PT. Pos Indonesia Persero Batam. (TA/ 2015)

Setiadi, Yadi. 2005. Desain dan Pengembangan Bahan Ajar. FPMIPA UPI, Bandung

Silayoi, P., Speece, M. (2005). The Importance of Attributes : a Conjoint Analysis Approach. April 2013, Vol.41.

Suhar Janti (2014) Analisis Validitas Dan reabilitas Dengan Skala Likert terhadap Pengembangan SI/TI Dalam penentuan Pngambilan Keputusan Penerapan Strategic Planning Pada Industri Garmen. Jurnal Manajement Informatika

Tjiptono, Fandy. 2008. Strategi Pemasaran. Yogyakarta: Andi OFFSET.

Wijaya,T, 2011. Manajemen Kualitas Jasa. Edisi1. Indeks. Jakarta

Yadi. 2005. Desain dan Pengembangan Bahan Ajar. FPMIPA UPI, Bandung 